\title{
All change...transcanal endoscopic ear surgery and house dust mite immunotherapy for allergic rhinitis
}

Endoscopic ear surgery is increasingly becoming commonplace in otological practice. ${ }^{1}$ Advantages include the panoramic views obtained with the use of the otoendoscope outside of the microscope's line of sight and higher magnification. One of the drawbacks is only having a single hand available for dissection. In addition, endoscopic ear surgery limits the ability to use standard drills because of the risk of damage to the endoscope and the limited workspace in the external auditory canal.

In this month's issue of The Journal of Laryngology \& Otology, Gardner et al. describe the feasibility and safety of using an ultrasonic bone aspirator in transcanal endoscopic ear surgery. ${ }^{2}$ Although the study was only performed on cadaveric temporal bones, it is a landmark study in that it illustrates the potential for powered instrumentation in endoscopic ear surgery, much like how functional endoscopic sinus surgery started out in its early days. The authors demonstrate the ease of bone removal with the ultrasonic aspirator (as demonstrated by the supplementary video material, available online at The Journal website ${ }^{3}$ ), with no additional complications and a significant reduction in the time taken to perform an atticoantrostomy, compared with standard bone curettage.

The efficacy, tolerability and safety of subcutaneous and sublingual immunotherapy for allergic rhinitis is hotly debated, and is the subject of the recently published European Academy of Allergy and Clinical Immunology guidelines on allergen immunotherapy. ${ }^{4,5}$ An article by Sahin et al. in this month's issue investigated the long-term effects of subcutaneous immunotherapy for house dust mite induced allergic rhinitis, based on a 10-year follow up. ${ }^{6}$ The authors conclude that subcutaneous immunotherapy is effective for house dust mite induced allergy, even 10 years after treatment. This study follows previous research which demonstrated that sublingual immunotherapy with house dust mite extracts is also efficacious for patients with house dust mite allergic rhinitis. ${ }^{7}$

Finally, an article by Luu et al. ${ }^{8}$ in this month's issue continues the theme of surgical simulation, 9,10 and evaluates a low-fidelity ear surgery simulator for developing otological microsurgical skills in lowresource settings. Simulation has become increasingly popular as a method of training surgeons in lowresource settings, with no risk to patient safety. Such a tool may be highly valuable in helping to train future surgeons to manage middle-ear disease.

JONATHAN FISHMAN
ROBIN YOUNGS
EDWARD FISHER
MUSHEER HUSSAIN
Senior Editors

References

1 Mitchell S, Coulson C. Endoscopic ear surgery: a hot topic? J Laryngol Otol 2017;131:117-22

2 Gardner EG, Sappington J, Arriaga MA, Kanotra SP. Ultrasonic bone aspirator use in endoscopic ear surgery: feasibility and safety assessed using cadaveric temporal bones. J Laryngol Otol 2017;131:996-9

3 Cambridge Core. Gardner et al supplementary material 1.In: https://www.cambridge.org/core/journals/journal-of-laryngology-and-otology/article/ultrasonic-bone-aspirator-use-inendoscopic-ear-surgery-feasibility-and-safety-assessed-usingcadaveric-temporal-bones /

F5B5FAFB80CC1A15DB7317FE926B8307\#fndtn-supplementary-materials [28 October 2017]

4 Durham SR, Penagos M. Sublingual or subcutaneous immunotherapy for allergic rhinitis? J Allergy Clin Immunol 2016;137: $339-49$

5 Roberts G, Pfaar O, Akdis CA, Ansotegui IJ, Durham SR, van Wijk RG et al. EAACI guidelines on allergen immunotherapy: allergic rhinoconjunctivitis. Allergy. Epub 2017 Sep 23

6 Sahin E, Dizdar D, Dinc ME, Cirik AA. Long-term effects of allergen-specific subcutaneous immunotherapy for house dust mite induced allergic rhinitis. J Laryngol Otol 2017;131: $1006-10$

7 Soh JY, Thalayasingam M, Ong S, Loo EX, Shek LP, Chao SS. Sublingual immunotherapy in patients with house dust mite allergic rhinitis: prospective study of clinical outcomes over a two-year period. J Laryngol Otol 2016;130:272-7

8 Luu K, Straatman L, Nakku D, Westerberg B, Clark M, Carter M. Evaluation of a low-fidelity ear surgery simulator in a lowresource setting. J Laryngol Otol 2017;131:1019-25

9 Clark MP, Westerberg BD, Mitchell JE. Development and validation of a low-cost microsurgery ear trainer for low-resource settings. J Laryngol Otol 2016;130:954-61

10 Avnstorp MB, Jensen PV, Dzongodza T, Matinhira N, Chidziva $\mathrm{C}$, Melchiors J et al. The introduction of emergency cricothyroidotomy simulation training in Zimbabwe contributed to the saving of two lives. J Laryngol Otol 2016;130:923-7 